\title{
樹林帯による漂流物捕捉効果を考慮した 数値解析による家屋被害関数
}

\author{
NUMERICAL ANALYSIS CONSIDERING THE EFFECT OF TRAPPING THE \\ FLOATAGE BY COASTAL FORESTS AND FRAGILITY CURVE OF HOUSES
}

\author{
小内克 $1 \cdot$ 田中規夫 2 \\ Aki ONAI , Norio TANAKA \\ 1学生会員 埼玉大学大学院 理工学研究科（テ338-8570 埼玉県さいたま市桜区下大久保255） \\ 2正会員 工博 埼玉大学大学院教授 理工学研究科（兼・埼玉大学研究機構レジリエント社会研究センター）
}

（テ338-8570 埼玉県さいたま市桜区下大久保255）

To estimate the fragility of wooden buildings (houses) in relation to the tsunami water depth and hydrodynamic force during the 2011 Great East Japan tsunami, a numerical simulation was conducted in two different regions using a nonlinear long wave equation model that includes the breaking or washout condition of trees and houses, and trapping function of driftwood by coastal forest. Fragility curves as a function of water depth, fluid force and moment by fluid force were analyzed for different level of house damages. Some differences exist especially for the fragility curve of washing out houses, but the curve has been improved by considering the trapping effect by trees, and become similar to that in the region where coastal forest was thin and breaching of embankment was not occurred.

Key Words : Great East Japan tsunami, trapping effect, fluid force index, moment index, classification of damage level

\section{1. はじめに}

津波による家屋被害の予測に関して，浸水深を用いた 評価が数多く行われてきた(例えば，首藤ら $\left.{ }^{1)}\right)$. また，家 屋群や構造物などによる局所的な加速や遮蔽による流速 の相違を反映できるよう，流体力を用いて家屋被害を評 価する研究 ${ }^{2}$ も昔から行われてきている．近年では，被 害を確率的に評価する手法も提案されてきている．例え ば，越村ら ${ }^{3)}$ は津波遡上現象の局所性と被害発生過程の 不確実性を考慮した「津波被害関数」を提案している. これは地震時における建物被害関数 ${ }^{4}$ を津波被害の場合 に適用したものであり, 主に浸水深, 流速, 流体力を算 出しそれらを利用した被害関数の構築が行われている.

しかし，流速・流体力に関しては解析の空間格子の大き さと家屋密集地域の抵抗評価による推定精度の問題があ るため，浸水深のみで主な結論が述べられている．流速 は，被害のあった現地で得られる痕跡浸水深と比較して 入手しにくい情報であり, 数值計算モデルの精度によっ て左右される. 田中ら5) は，樹木の破壊形態による抵抗 変化, 流失後の家屋が漂流している際に津波に与える抵
抗や隣接家屋にせき止められる際に働く付加抵抗を評価 することによって，数值計算の精度が向上することを確 認している.

東北地方太平洋沖地震により発生した津波が襲来した 際には，岩手県や宮城県などの沿岸では海岸林が多数な ぎ倒された，一方，仙台平野や相馬港においては，未破 壊の樹林帯が流木化した樹木や自動車などの漂流物を捕 捉することによって直背後の家屋被害を軽減したことも 確認されているの . 家屋被害関数を構築する際には地形 条件や建物配置などの地域特性をはじめ, 家屋・樹木の 破壊, 漂流物の捕捉効果といった複雑な津波の遡上過程 で生じる現象の影響も含む必要がある.

以上を踏まえ, 本研究は，1)破壊や浮遊物の輸送・捕 捉を伴う巨大津波の遡上現象における水深・流速の算出 精度を向上させること，2)津波による家屋被害関数を， 流速影響を加味したパラメータである流体力と流体力に よるモーメントで表現し，フラジリティ曲線の汎用化を 行うこと, を研究目的とした. 目的を達成するため, 樹 木・家屋の抵抗評価を行っている既往の数值計算モデル 5)に，樹林帯が漂流物を捕捉する影響を組み込んだ上で 解析を行うものとする. 


\section{2. 研究方法}

\section{(1) 樹林破壊 · 家屋破壊を含む津波の解析手法}

既往のモデルすをもとに，破壊を伴う津波現象の数值 解析手法の改良を行った. 既往のモデルとの相違点や改 良点を，解析条件等も含めて以下の (a) (d)に示寸.

\section{(a) 数值解析モデル}

一般的な二次元非線形長波モデルにグリッドの水平方 向空隙率を考慮したモデル (連続式(1), 運動方程式(2), （3）を用い，水平方向の渦動粘性はSDS乱流モデルワを 用いて計算を行った.

$$
\begin{gathered}
\theta \frac{\partial \zeta}{\partial t}+\frac{\partial Q_{x}}{\partial x}+\frac{\partial Q_{y}}{\partial y}=0 \\
\frac{\partial Q_{x}}{\partial t}+\frac{\partial}{\partial x}\left(\frac{Q_{x}^{2}}{\theta h}\right)+\frac{\partial}{\partial y}\left(\frac{Q_{x} Q_{y}}{\theta h}\right)+g \theta h \frac{\partial \zeta}{\partial x}+\frac{\theta}{\rho} \tau_{b x}+\frac{\theta}{\rho} F_{x}-E_{v x}=0 \\
\frac{\partial Q_{y}}{\partial t}+\frac{\partial}{\partial x}\left(\frac{Q_{x} Q_{y}}{\theta h}\right)+\frac{\partial}{\partial y}\left(\frac{Q_{y}^{2}}{\theta h}\right)+g \theta h \frac{\partial \zeta}{\partial y}+\frac{\theta}{\rho} \tau_{b y}+\frac{\theta}{\rho} F_{y}-E_{v y}=0 \\
\left(\tau_{b x}, \tau_{b y}\right)=\frac{\rho g n^{2}}{\theta^{2} h^{7 / 3}} \times\left(Q_{x} \sqrt{Q_{x}{ }^{2}+Q_{y}^{2}}, Q_{y} \sqrt{Q_{x}{ }^{2}+Q_{y}^{2}}\right) \\
\left(F_{x}, F_{y}\right)=\gamma \frac{1}{2} \rho C_{D-a l l} b_{r e f} \frac{1}{\theta^{2} h} \times\left(Q_{x} \sqrt{Q_{x}{ }^{2}+Q_{y}{ }^{2}}, Q_{y} \sqrt{Q_{x}{ }^{2}+Q_{y}{ }^{2}}\right) \\
E_{v x}=2 \frac{\partial}{\partial x}\left(v_{e} \frac{\partial Q_{x}}{\partial x}\right)+\frac{\partial}{\partial y}\left(v_{e} \frac{\partial Q_{x}}{\partial y}+v_{e} \frac{\partial Q_{y}}{\partial x}\right) \\
E_{v y}=2 \frac{\partial}{\partial y}\left(v_{e} \frac{\partial Q_{y}}{\partial y}\right)+\frac{\partial}{\partial x}\left(v_{e} \frac{\partial Q_{x}}{\partial y}+v_{e} \frac{\partial Q_{y}}{\partial x}\right)
\end{gathered}
$$

ここに, $x, y$ : 平面座標, $Q_{x}, Q_{y}: x, y$ 方向の線流量 $\left(Q_{x}=\theta h V_{x}, Q_{y}=\theta h V_{y}\right), \theta:$ グリッドの水平方向空隙率, $V_{x}$, $V_{y}: x, y$ 方向の流速成分, $t:$ 時間, $h:$ 全水深 $(h=$ $\left.h_{0}+\zeta\right), h_{0}$ : 静水深 (陸上では負の值) , $\zeta$ : 水位, $n$ : マニングの粗度係数, $\gamma$ : 樹木密度, $\rho$ : 水の密度, $g$ : 重 力の加速度, $v_{e}$ : 渦動粘性係数, $\tau_{b x}, \tau_{b y}$ : 底面摩擦応 力, $F_{x}, F_{y}$ : 単位面積あたりの樹林による抗力, $b_{r e f}$ : 家 屋幅もしくは樹木の胸高直径, $E_{w}, E_{w}$ : 渦粘性力のそ れぞれ $x, y$ 方向成分である. 底面摩擦応力はマニングの 粗度係数 $(0.025)$ を用いて評価した. また， $C_{D \text {-all }}$ は樹 形を考慮した抗力係数であるが，対象地域の樹木はク口 マツ・アカマツであり, 枝が少なかったため, $C_{D \text {-all }}=1$ (以後 $C_{d}$ ) とした.

水平方向の空隙率に関しては, 樹林帯や家屋が存在す ることによる局所的な水のせき上げや縮流の影響を考慮 することに加え, 後述する樹林带の漂流物捕捉効果を検 討するために組み込んだものである.

数值計算は基礎式を差分式に变換して行った. 差分化 に関しては，空間的にはstaggered grid，時間的にはleapflog schemeを用いた。

(b) 数值計算領域ならびに境界条件

計算領域に関しては，樹林帯が漂流物を捕捉すること によって流れがせき止められ，直背後の家屋が守られた
地点が数か所確認された仙台市宮城野区(Region A), 海 岸林が少なく沿岸に家屋が数多く立地する若林区荒浜 (Region B)を選定した. 家屋配置は, Region Aは堤防付 近から内陸まで連続的に立地しており， Region Bは堤防 付近から内陸1000mまでに793軒と非常に密集している.

標高データは国土地理院の $2 \mathrm{~m} \times 2 \mathrm{~m}$ のデータを用いて $10 \mathrm{~m} \times 10 \mathrm{~m}$ のグリッドを作成した。 図-1には計算に使用 した海底地形の岸沖方向断面図（類似しているので Region Bのみ)を示す．津波の造波境界条件は水深 $200 \mathrm{~m}$ の部分において周期30分で発生させ，宮城県中部沖の GPS波浪計で観測された津波波高と汀線付近の痕跡浸水 深を概ね再現する条件で設定している.

樹木や家屋は抗力を与える物体として扱かわれ，計算 の中で後述する破壊・流失判定を時々刻々行い，その破

壊・流失に応じて抗力係数を変化させた.

（c）樹木 · 家屋の破壊 ·流失判定モデル

樹木の破壊に関しては，既往モデルロを使用した．本 研究の対象領域に繁茂するマツの場合に当てはめ, 式 (8),(9)の関係から破壊判定を行った.

$$
\begin{gathered}
M=F \times \frac{h}{2}=\frac{1}{2} C_{d} \rho u^{2} h d_{B H} \frac{h}{2} \\
M_{c r i}=k d_{B H}{ }^{3}
\end{gathered}
$$

ここに, $d_{B H}(\mathrm{~m})$ : 樹木の胸高直径, $u(\mathrm{~m} / \mathrm{s})$ : 断面平均流 速， $k$ : 破壊限界モーメントを表寸次元付き定数で，田 中ら 妾参考に硬い樹木の $2 \times 10^{6}\left(\mathrm{~N} / \mathrm{m}^{2}\right)$ を採用した.

胸高直径などの樹木データに関しては, 現地調查より 得られたものを使用した. 貞山運河より海側と陸側で生 育状況が異なっていたため，それぞれ平均化した。ま た，海側では破断・倒伏が確認されたため，津波による 抗力モーメント（式(8)）が樹木破壞限界モーメント（式 （9)）を超えたとき，樹木の破断・倒伏を判定し，抗力係 数 $C_{d}=1.0$ を 0.2 に変化させることで破壊後にも流れに抵抗 する状況を再現した．陸側では根鉢ごと転倒する破壊や 流失が広範囲で確認された。 液状化の影響が報告されて いることから，地盤が海側よりも弱くなっていたと考え られる。 そのため, 田中ら ${ }^{9}$ を参考に樹木転倒限界モ一 メント $M_{\text {ocri }}\left(=5 \times 10^{4} d_{B H}^{2}\right)$ 老式(9)の変わりに設定し て, 流失と判定された場合に $C_{d}$ を变更した.

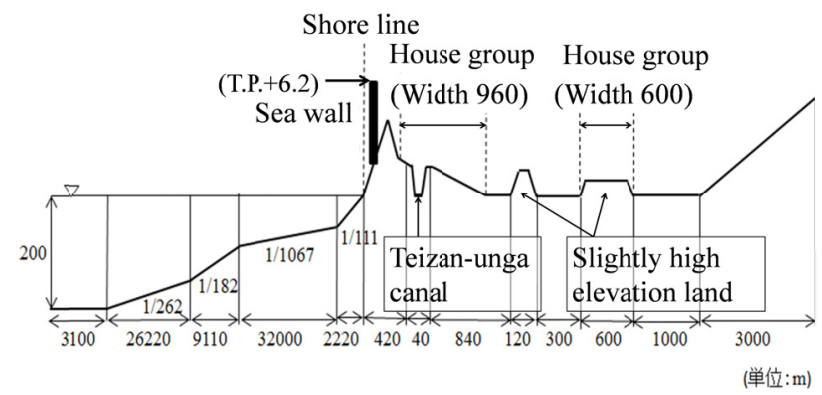

図-1 Region B（若林区荒浜）の地形断面 


\section{（d）樹林帯による漂流物捕捉効果}

宮城野区では，漂流物が樹林帯に捕捉されたことに よって樹林帯直背後の家屋が流失せずに守られたことが 報告されている6)。その現象が確認された状況を図-2に 示す。また，筆者らは流木の衝突実験より比重が1の生 木に近い条件で，かつ流れのフルード数が常流でも1に 近い場合には物体を回りこむ下降流が生じ，流木が衝突 した物体前面部の底面に堆積する現象が生じることを確 認している (未発表）。そこで，本計算では，樹林帯が 陸域方向に連続して存在し，海側のグリッドで流失，陸 側のグリッドで未破壊と判定された場合に，流失した樹 木を未破壊樹木が樹木の下部で捕捉するという処理を追 加し計算を行った. ただし，未破壊樹木の上部で捕捉さ れた場合，付加的な抵抗によるモーメントが作用し，支 える樹木も破壊されてしまう可能性が高い。しかし，図 -2の状況を踏まえ, 本研究では付加的な抵抗は樹木に直 接的には作用しないとした。捕捉した場合には，グリッ ドの鉛直方向空隙率 $\theta_{v}$ を式(10)より計算し，グリッドの 水平方向空隙率 $\theta$ として与え計算を行った. また，樹木 全てが一列に積み重なって捕捉されることは考えにくい ため，水深の半分の高さまで重なった場合は二列目に重 なるとし， $\theta_{v}$ の閾值を 0.5 として計算を行った， $\theta_{v}$ の計算 は前述の抗力係数と同様に樹木の流失・残存の状況を判 定しながら時々刻々更新する形で数值計算に適用した.

$$
\theta_{v}=1-\left(\frac{m \times d_{B H} \times H_{t}}{d y \times h}\right)
$$

ここに, $m: 1$ グリッド当たりの樹木の本数, $H_{t}$ : 樹高, $h:$ 水深である.

\section{（2）家屋の現地被害実態}

対象領域の家屋の破壊について，全壊(流失)(Washed away), 全壊(Collapsed), 半壊(Complete damage, Moderate damage, Major damage), 未破壊(Minor damage)の4つに分 類(括弧内はSuppasri $\check{(}^{10)}$ の定義)し，現地被害実態の整理 を行った. 方法に関しては, 震災前後の航空写真などか ら簡易的に判断できる手法で行った．全壊(流失)は家屋 が基礎のみを残し流失しているものとした．全壊は構造 上に久陥が生じたものとして，柱破壊(2本以上)，壁破 壞(3割以上の面積），家屋の全体に歪みなどがあるもの とした。半壞は構造には影響を与えない程度の破壊とし， 扉や空の破壊，壁の破壊(3割以内の面積) とした．未破 壊は浸水した痕跡がガラスに確認できるものや，全体的 に破壊が生じていないものとした.

以上のように分類した 2 地域の家屋の破壊状況を樹木 の残存状況々合わせて図-3に示寸．本研究では，家屋被 害関数を算出する際にこのデータを使用する.

\section{（3）家屋流失判定モデルの検証}

家屋破壊に関しては4種類に分類したが，数值計算上
では流失(Washed away)と残存(Collapsed〜Minor damage) のみの判定しか行っていない，そのため，式(11)を用い て適合率Wを算出し，家屋流失の検証を行った。

$$
W=\frac{w w+n n}{w w+n n+w n+n w} \times 100
$$

ここに，ww：計算結果と現地観測で家屋の状態がどち らも流失 $(w), n n$ ：計算結果さ現地観測で家屋の状態が どちらも残存 $(n), w n$ ：計算結果が流失で現地観測が残 存, $n w$ : 計算結果が残存で現地観測が流失, を表す.

\section{(4) 家屋被害関数の算出}

家屋の被害確率に関しては式(12)，(13)より流失，全 壊以上の破壊が生じる確率を旮れぞれ算出した。

$$
\begin{aligned}
& P_{d}(z)=\frac{a(z)}{a(z)+b(z)+c(z)+d(z)} \times 100(\%) \\
& P_{d}(z)=\frac{a(z)+b(z)}{a(z)+b(z)+c(z)+d(z)} \times 100(\%)
\end{aligned}
$$

ここに，ある津波外力 $z$ の時， $a$ : 全壊(流失)した 家屋 件数, $b$ : 全壊した家屋件数, $c$ : 半壊した家屋件数, $d:$ 浸水のみで破壊がない家屋件数である.

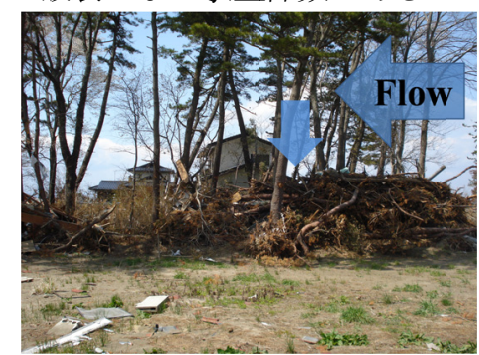

図-2 漂流物捕捉が観測された地点)(宮城県仙台市宮城野区)
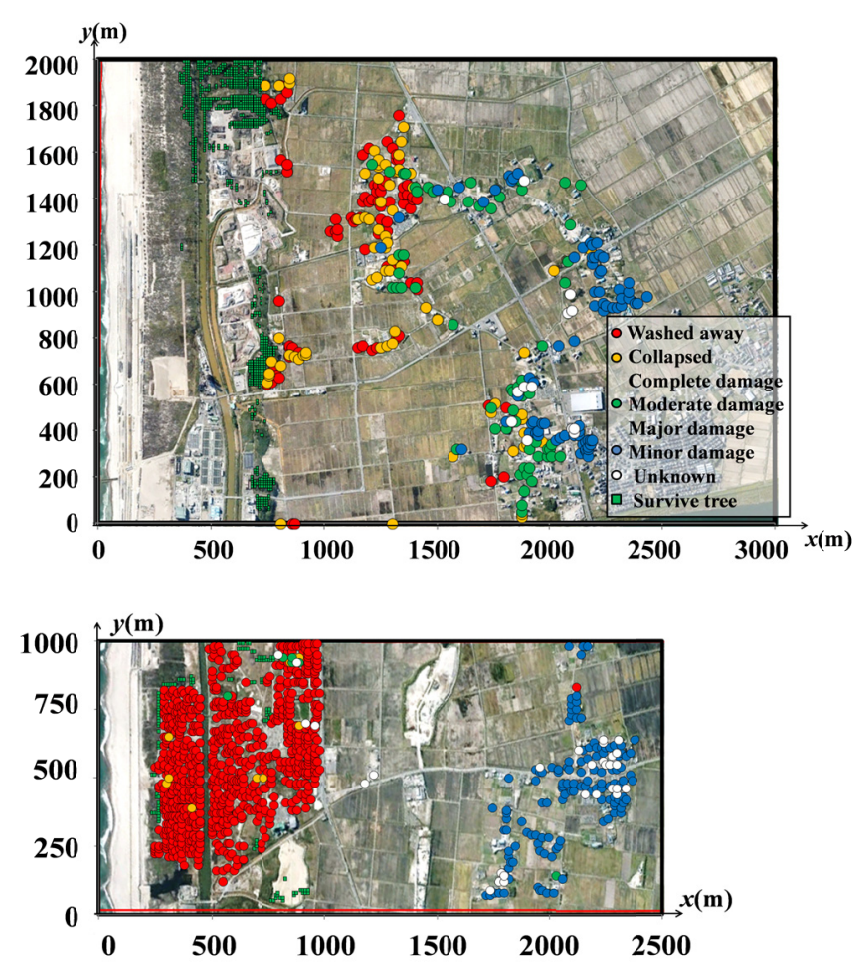

図-3 現地調查による各地点の破壊分類結果 (上段 : Region A, 下段 : Region B) 
家屋被害関数の算出に関しては，回帰分析の適合度に より正規分布と対数正規分布を選択する．本研究では， 式(14) に示される対数正規分布を使用した.

$$
\begin{aligned}
& P_{D}(z)=\Phi\left[\frac{\ln z-\lambda}{\xi}\right] \\
& =\int_{-\infty}^{z} \frac{1}{\sqrt{2 \pi} \xi t} \exp \left(-\frac{(\ln t-\lambda)^{2}}{2 \xi^{2}}\right) d t
\end{aligned}
$$

ここに，zは津波外力指標で， $\lambda, \quad \xi$ はn $x$ の平均值と標 準偏差である.

\section{3. 解析結果および考察}

\section{（1）数値解析結果の検証 : 浸水深と家屋破壊の適合率}

図-4に東北地方太平洋沖地震津波合同調査グループ11) と本研究で行った痕跡調査と数值解析から得られた浸水 深の比較図を示す. 痕跡の種類に関しては, 海岸林や大 型構造物など局所的なせきあげが予想されるものと，家 屋や寺院などで調査された代表的な水位を観測できるも のを区別して整理した．解析值の方が浸水深を過小評価 している箇所も数地点見受けられるが，ほとんどの地点 で解析值と一致するため，家屋被害を評価する十分な精 度を持った解析結果であると言える. 以下の(a), (b)で は，漂流物捕捉効果を確認するために，漂流物捕捉効果 ありのケース(以降Case F) と共に，捕捉効果なしのケー ス(以降Case NF)の結果(家屋と樹木の流失・残存の解析 結果と現地観測との適合率)を合わせて示す。なお, Case NFの場合は水平方向の空隙率も考慮していない.

\section{(a) RegionAでの解析結果 (図-5)}

対象領域内の総家屋数は298軒（現地観測で流失が確 認できたのは82軒，残りの216軒は残存）であった。解 析結果より家屋被害の適合率はCase NFで63.8\%, Case F で76.0\%であり，漂流物捕捉効果を考慮したことによっ て精度が向上し，概ね現地の被害状況を再現できたと考 えられる. 詳細は樹林帯が存在するA1 A5地点に分けて 考察する. A1地点は，現地観測でやや残存樹木があっ た地点だが，Case Fでは過小に樹木の残存が判定された。

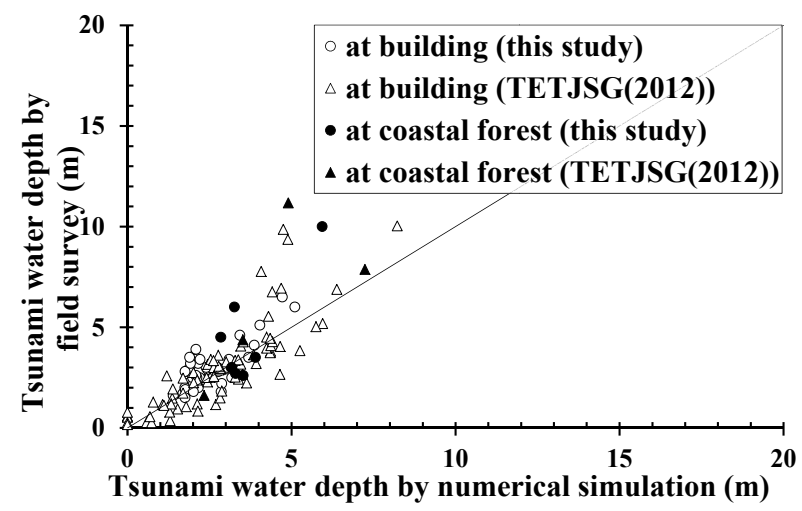

図-4 現地調査と数值解析の浸水深の比較
これは，Case Fでは水平方向・鉛直方向に空隙率を考慮 しているため，流速が大きくなったためであると考えら れる. A2 地点では現地観測では残存した樹木が多く実 際に漂流物の捕捉によって直背後の家屋が流失を免れた ことが確認された地点となっている. しかし，数值解析 では地形の影響などにより Case NF，F 共に再現できな かったと考えられる. そのため, 樹林帯背後の家屋で現 地観測では残存となっている箇所も数值計算上では両 ケース共に流失と判断され，樹林帯の漂流物捕捉効果を 再現できなかった．A3地点は，現地観測ではそれほど 大きな残存は確認されないが，Case Fでは多くの樹林帯 を残存と判定している. 従って，A3地点の背後の家屋 群に向から津波の勢いを弱めたことで，Case NFでは評 価できなかったその家屋群の判定が現地の状況に近くな
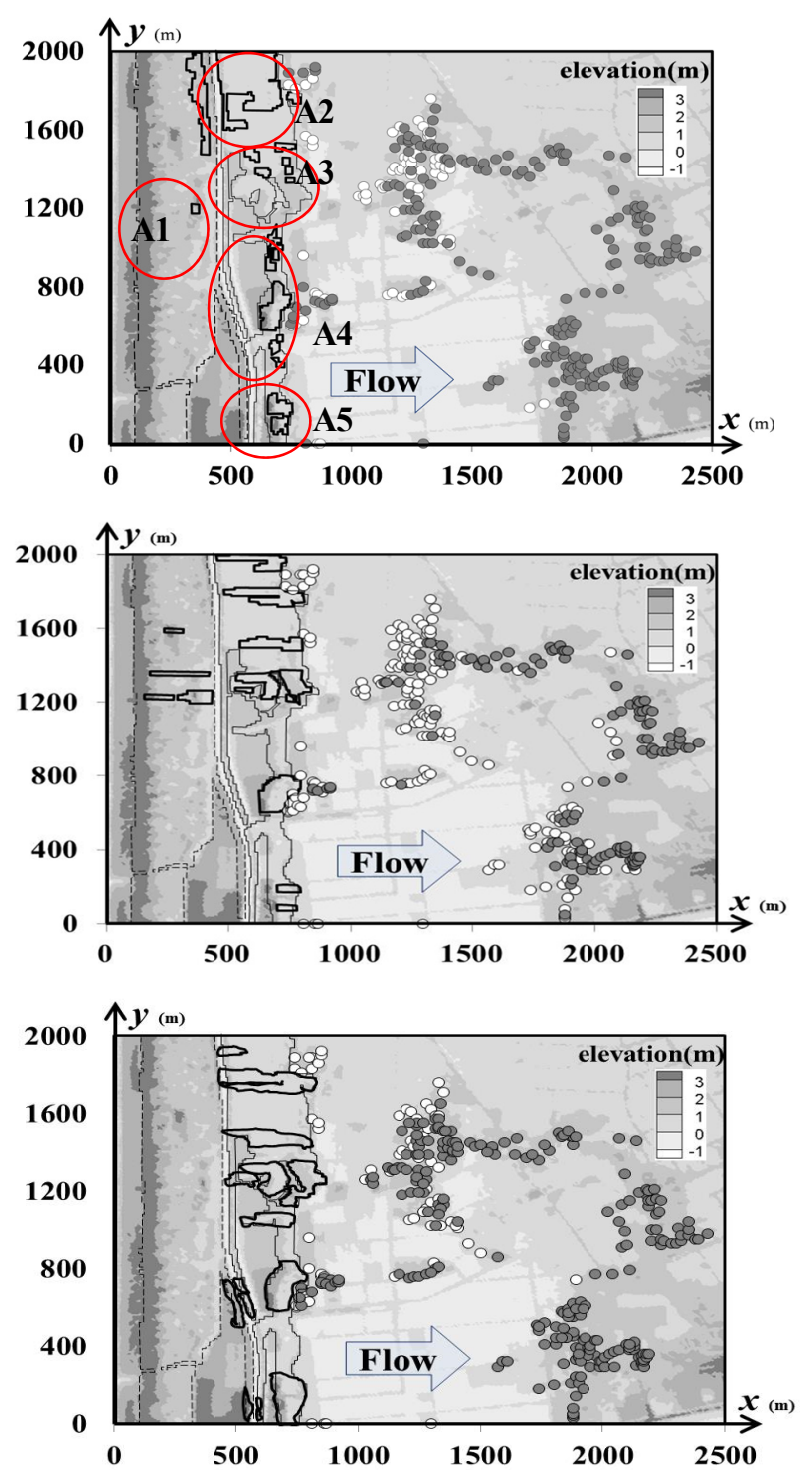

the building was washed away.

the building was mostly or partly broken, but not washed away. the trees in the area were washed away or overturned.

the tree trunks in this area were bent or broken but not washed away. the trees in the area withstood the force.

図-5 現地観測と解析結果の比較(Region A)：上段 : 現地観測, 中段 : 漂流物捕捉なし, 下段 : 漂流物捕捉あり 
ったと考えられる．A4地点は，A2地点と同様に漂流物 の捕捉効果が確認された箇所である. Case NF，F共に現 地観測と同様に樹木の残存を評価できている．その直背 後の家屋群の破壊判定に関してはCase NF，Fで異なり，

Case Fの方が現地観測に近い判定となっている. これは, 漂流物の捕捉効果により家屋が守られた状況が再現でき ていることを示している. A5地点は, Case NFにおいて 樹木の破壊状況を再現できずに, $(x, y)=(1600,350)$ 付近の 家屋群の破壊状況も再現できなかった. Case Fに関して は，樹木の破壊判定が現地観測に近い形でできたことに より津波を減衰させ， $(x, y)=(1600,350)$ 付近の家屋群の破 壊状況も再現できている.

\section{(b) RegionBでの解析結果 (図-6)}

対象領域内の総家屋数は936軒（現地観測で流失が確 認できたのは762軒，残りの174軒は残存）であった．解 析結果より家屋被害の適合率はCase NFで96.8\%, Case F で95.7\%であり，かなり精度の高い結果となった。詳細 は, 樹林帯を切り開いた領域に位置する家屋群S4(座標 $x$ $=270-980 \mathrm{~m}$ ) とそれより内陸に位置する家屋群S3(座標 $x$ $=1720-2380 \mathrm{~m} ）$ に分けて考察する. 現地観測より, 家屋 群S4のほぼすべてが流失した。解析結果を見ても両ケー スとも概ね再現できていることがわかる．家屋群S3につ いてはS4より700m以上内陸に分布し，標高も1-2m程高 くなるので遡上の際に津波が減衰し，現地観測ではほぼ すべてが残存と確認された. また, Region BではCase F よりもCase NFの適合率が高くなっている. 理由として は，下段の赤丸で囲まれた地点のように，漂流物捕捉効 果の考慮により，樹木の破壞判定流速が過小評価となり， 現地観測では流失していても解析上残存と判定され，そ の樹木の直背後の家屋も残存と判定されたと考えられる.

\section{(2) 漂流物捕捉効果によるフラジリティ曲線への影響}

漂流物捕捉効果を数值計算に取り入れることによって 局所的には精度低下があるが，全体的に解析の精度は向 上した. 以下では，Case NF，Fより算出された津波外力 を用いて家屋被害関数の導出を行い, 漂流物捕捉効果に よるフラジリティ曲線への影響を比較する. 全壊(流失), 全壊以上のフラジリティ曲線をそれぞれ図-7,8に示す.

\section{(a) 全壊 (流失)のフラジリティ曲線}

図-7より，全壊(流失)の被害関数には各津波力で地域 差が存在する. Case NFに関しては, 破壊確率 $50 \%$ 時の 浸水深で $90 \mathrm{~cm}$, 流体力指標 $\left(u^{2} h: u\right.$ は断面平均流速, $h$ は浸水深）で $13.7 \mathrm{~m}^{3} / \mathrm{s}^{2}$ ， モーメント指標 $\left(u^{2} h^{2}\right)$ で $31.5 \mathrm{~m}^{4} / \mathrm{s}^{2}$ 程度である. Case Fに関しては, 浸水深で $20 \mathrm{~cm}$, 流体力指標で $8.9 \mathrm{~m}^{3} / \mathrm{s}^{2}$, モーメント指標で $17.8 \mathrm{~m}^{4} / \mathrm{s}^{2}$ 程度である. Case NFよりも漂流物捕捉効果 を考慮するなど高精度な解析を行ったCase Fの方がより 地域差が少ないことがわかる、全壊(流失)のフラジリ ティ曲線に関しては，地域差がやや大きいため改良す心゙ き点や課題を残すが，数值計算の精度を上げることで汎
用化につながることが示唆された.

(b) 全壊以上のフラジリティ曲線

図-8より，全壞以上のフラジリティ曲線に関しては,
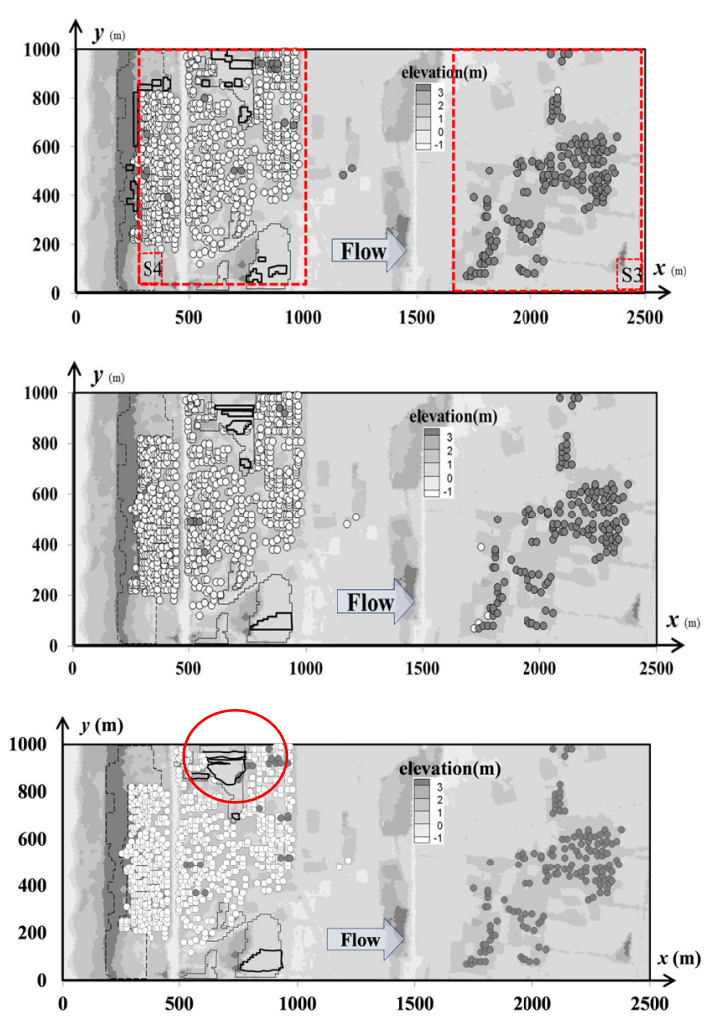

図-6 現地観測之解析結果の比較(Region B) : 上段 : 現地観 測, 中段 : 漂流物捕捉な几，下段：漂流物捕捉あり
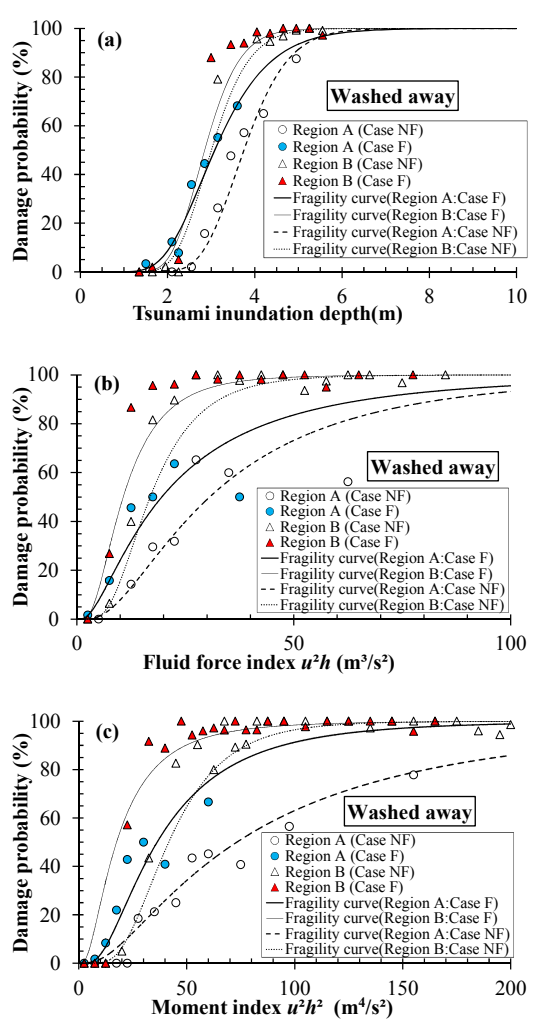

図-7 各指標による津波被害関数(全壊(流失))，(a)津波浸水深, (b)流体力指標，(c)モーメント指標 
特に流体力指標・モーメント指標で地域差が非常に少な かった. Case NFに関しては，破壊確率50\%時の浸水深 で $20 \mathrm{~cm}$, 流体力指標で $0.2 \mathrm{~m}^{3} / \mathrm{s}^{2}$ ，モーメント指標で $0.7 \mathrm{~m}^{4} / \mathrm{s}^{2}$ 程度の差である. Case Fに関しては, 浸水深で $35 \mathrm{~cm}$, 流体力指標で $0.2 \mathrm{~m}^{3} / \mathrm{s}^{2}$ ，モーメント指標で $1.7 \mathrm{~m}^{4} / \mathrm{s}^{2}$ 程度の差である. 両ケース共に, 各指標で非常 に小さな地域差となった理由として, 全壊(流失)と全壊 の境界を解析が表現できたことが挙げられる．浸水深の フラジリティ曲線に関しては, Case Fの方がより地域差 が大きくなった．考えられる理由としては，グリッドの 水平・鉛直方向空隙率を考慮したことによって流速の見 積もりが大きくなってしまい, 低い水深でも加速された 流れによって破壊と判定された場合が多く含まれるため ではないかと推測する，そういった原因に関しては，漂 流物捕捉効果のモデル化や閾值の与え方が影響している ものと思われる. 今後は, 漂流物捕捉に関する実験など も行いつつ更なるモデルの精度向上をはかる予定である.

\section{4. おわりに}

本研究では，樹林帯や構造物の破壊現象，漂流物捕捉 効果を取り込んだ津波解析モデルを構築し, 津波外力を 用いて, 地域差の少ないフラジリティ曲線の汎用化を検 討した. その結果,

(1) 樹林帯による漂流物の捕捉効果により，地域全体と しての家屋破壞判定の精度は向上した.
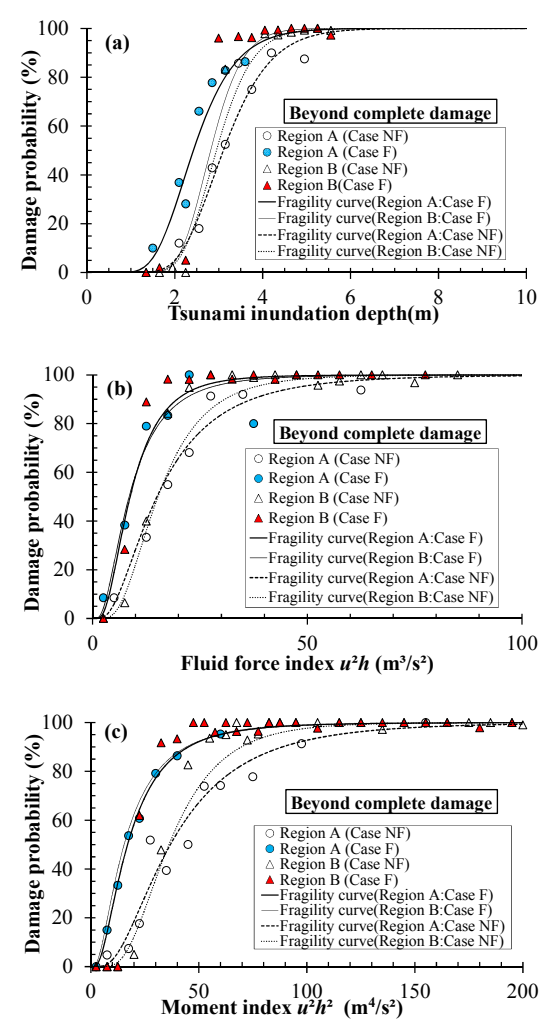

図-8 各指標による津波被害関数(全壊以上), (a)津波浸水深, (b)流体力指標, (c)モーメント指標
(2) Region A(海岸林が厚く破堤が生じた地域) とRegion $\mathrm{B}($ 海岸林が薄く破堤が生じなかった地域)の全壊以上の 家屋被害関数は類似したものとなったことから，汎用性 の高いものが導出された.

（3）地域により樹木の残存を過大に評価してしまい，直 背後の家屋破壞判定を劣化させる場合もある. この場合, 漂流物捕捉効果のモデル化が影響していると考えられる ため, 更なる高精度化が課題である.

謝辞 : 本研究の一部に, 科学研究費補助金基盤研究B

（No. 24310127，代表 : 田中規夫）を使用した. 記して 謝意を表します.

\section{参考文献}

1) 首藤伸夫: 津波の強度と被害, 東北大学津波工学研究報告, 第9号,pp.101-136, 1992.

2) 羽鳥徳太郎: 津波による家屋の破壊率, 地震研究所彙報, Vol.59, pp.433-439, 1984.

3）越村俊一, 行谷祐一, 柳澤英明: 津波被害関数の構筑, 土 木学会論文集 B, Vol65, No4, pp.320-331, 2009.

4) 村尾 修, 山崎文雄: 自治体の被害調查結果に基づく兵庫 県南部地震の建物被害関数, 日本建築学会構造系論文集, 第 527 号, pp.189-196, 2000.

5) 田中規夫, 八木澤順治, 飯村耕介, 近藤康太 : 津波による 海岸林および流失家屋が家屋被害に与える影響, 土木学会 論文集 B2, Vol.68, pp.301-305, 2012.

6) Tanaka, N.: Effectiveness and limitations of coastal forest in large tsunami: Conditions of Japanese pine trees on coastal sand dunes in tsunami caused by Great East Japan Earthquake, J. Jap. Soc. of Civil Engineers, Ser. B1 (Hydraulic Engineering), Vol. 68, No. 4, pp.II_7-II_15, 2012.

7) 灘岡和夫,八木宏 $: \operatorname{SDS} \& 2 \mathrm{DH}$ モデルを用いた開水路水平 せん断乱流の数值シミュレーション, 土木学会論文集, No.473/II-24, pp.35-44, 1993.

8）田中規夫, N. B. Thuy, 谷本勝利 : 熱帯性海岸樹木の破壊限 界を考慮した防潮林の津波低減効果の評価, 土木学会論文 集B, Vol.66, No.4, pp.434-443, 2010.

9）田中規夫, 八木澤順治, 佐々木寧, 福岡捷二 : 河道内樹木 の洪水破壞形態と破壞限界值の基盤土壌条件による相違, 水工学論文集, 第 52 巻, pp.649-654, 2008.

10) Suppasri, A., Mas, E., Charvet, I., Gunasekera, R., Imai, K., Fukutani, Y., Abe, Y. and Imamura, F.: Building damage characteristics based on surveyed data and fragility curves of the 2011 Great East Japan tsunami, Natural Hazards, Vol.66, pp.319-341, 2013.

11) The 2011 Tohoku Earthquake Tsunami Joint Survey Group (TETJSG), 2012. Field Survey Results. http://www.coastal.jp /tsunami2011/index.php?Field\%20survey\%20results(accessed August 28, 2013).

(2014. 9. 30受付) 